\title{
Research on Navel Orange Safety Production Information Management System
}

\author{
Huoguo Zheng ${ }^{1,2}$, Shihong Liu ${ }^{1,2}$, Liping Zheng ${ }^{3}$, and Jiayou Zhong ${ }^{3}$
}

${ }^{1}$ Key Laboratory of Digital Agricultural Early-warning Technology of Ministry of Agriculture,

The People's Republic of China, Beijing 100081, Beijing, China

${ }^{2}$ Agricultural Information Institute of Chinese Academy of Agriculture Science, Beijing 100081, Beijing, China

${ }^{3}$ Agricultural Information Institute of Jiangxi Academy of Agriculture Science, Nanchang 330200, Jiangxi, China

huoguo@caas.net.cn, lius@mail.caas.net.cn, 1sny@163.com, zjyou666@vip.163.com

\begin{abstract}
To deal with the incident, and guarantee the quality safety of navel orange, traceability system are used to record the information from tree planting to fruit sale. Navel orange safety production information management system, which manages the whole process from tree planting to circulation, achieves the entire information management except sale step of the navel orange food chain, is the core and foundation of navel orange traceability system. This paper discusses the basic function of navel orange safety production information management system based on analyses the whole business process, design the main function modules of the system according to GAP(Good Agricultural Practice), implement the system with the strategy of RBAC(Role Based Access Control based).
\end{abstract}

Keywords: navel orange, safety production information management system, GAP, RBAC.

\section{Introduction}

Navel orange is one of characteristic agricultural products in the middle of china. Gannan is the advantageous product area of navel orange determined by ministry of Agriculture in China. Gannan is the famous base for navel orange, where is known as "town of navel orange in China". Many counties have taken navel orange as an important tool for local farmer income. The navel orange produced in gannan has many unique features, such as large shaped, bright color, crisp flesh and good taste.

However, the incidents occurred in recently years, such as "dyeing navel orange" in Hong Kong in 2004, "bactrocera minax" in guangyuan city in 2008, Sichuan province, have damaged the orange industry in south of china. For example, The "dyeing navel orange" incident made $70 \%$ order in Hong Kong cancellation, the price of navel orange fell sharply in 2004. In 2008, affected by the "bactrocera minax" incident, all of the consumers don't want to buy navel orange in china. These events cause severe economic losses to fruit growers. 
To deal with the incident, and guarantee the quality safety of navel orange, traceability system are used to record the information from tree planting to fruit sale, which also called "management from orchard to table" [1]. There are three main meaning to construct traceability system: one is to make consumers know the quality safety conditions of the product they bought, the second is standardized production process of enterprises ,ensure the quality safety of products produced, and the third is to find the root causes when the food safety issues happened [2].

Navel orange safety production information management system, which manages the whole process from tree planting to circulation, achieves the entire information management except sale step of the navel orange food chain. It provides the safety information for consumer-oriented traceability system, and is the core and foundation of navel orange traceability system.

This paper point out the basic functions and modules of the navel orange safety production system based on business processes analysis, indicate the information the system should be recorded, then implementation the system according to the GAP(Good Agricultural Practice).

\section{$2 \quad$ Navel Orange Safety Production System Analysis}

\subsection{Navel Orange Production Process Analysis}

Generally, from tree planting to bear fruits need 2-3 years for navel orange tree. And it need 280-300 days from blooming to outcome when the navel tree is in produce fruiting period. A lot of operations should be taken from navel orange tree planting to fruit sales [3].

There are 9 main steps from navel orange tree planting to navel orange fruit transportation: orchard selection, tree planting, irrigation and fertilization, insects and disease control, fruit picking, washing and packing, storage and transportation (shown as Fig. 1).

\subsection{System Function Analysis}

For the navel orange safety production information management system, which functions include two aspects: the first is achieve the core business process management from fruit tree planting to transportation, including orchard management, production management, harvesting management, process management, and the second aspect is related to personnel management for system, such as user management, permissions management.

Essentially, the core of navel orange safety production information management system is to manage the information about production and processing affect the quality and safety of navel orange. The information the system manage can be divided into three kinds: 


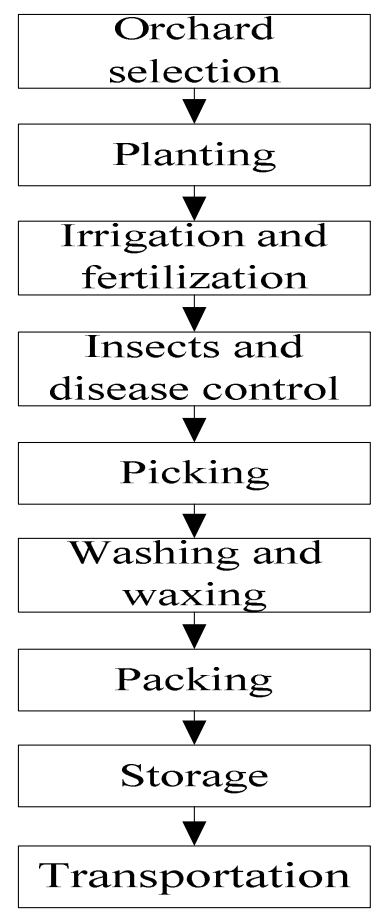

Fig. 1. 9 main steps from orchard to market of navel orange

The first type information is the quality safety information during navel orange production, including producing area conditions information (such as detection information of the origin water, soil and air); production process information (such as irrigation and fertilization information, major climate disaster information, diseases and insect pests, pesticide use information); information about picking and postpicking measures; cleanser, disinfectant, wax information during the process; packing information, storage surrounding information (such as place, temperature and sanitary condition), information about transportation.

The second type information is the information about organization, company and related personnel involved navel orange planting and processing, including ownership of the orchard, manager and worker of the orchard, processing company and worker of the company, transportation enterprise and vehicle.

The third type information is the user information of the navel orange safety production information management system, including basic information of the system user, login name, password, and the information of the user's role permissions. These users can log into the system, view information, input and maintain information within limits of authority. The user maybe the person himself mentioned above, such as ownership, manager or worker of the orchard, he also can be others who has the rights of operator or transporter. 


\section{Design of Navel Orange Safety Production Information Management System}

\subsection{Principles of System Design}

Navel orange safety production information management system was designed based on the principle of GAP (Good Agricultural Practices).

Good Agricultural Practices are a collection of principles to apply for farm production and post-production processes, resulting in safe and healthy food, while taking into account economical, social and environmental sustainability. GAPs can be applied to a wide range of farming systems and at different scales. They are applied through sustainable agricultural methods, such as integrated pest management, integrated fertilizer management and conservation agriculture. It relies on four principles: economically and efficiently produce sufficient (food security), safe (food safety) and nutritious food (food quality); sustain and enhance natural resources; maintain viable farming enterprises and contribute to sustainable livelihoods; meet cultural and social demands of society.

As for navel orange safety production information management system, GAP is applied to control the common quality safety hazard in planting, harvest, cleaning, packing and transportation. For example, worker will be guide to use environmentally friendly manure, low-toxic low residue of pesticides.

\subsection{System Function Module Design}

In order to manage the information related to quality and safety from navel tree planting to fruit transportation, the function of navel orange safety production information management system should include at least the following 7 modules: system user management, navel orange standards management, orchard management, production control, picking management, processing management, storage and transportation management (shown as Fig 2).

In system user management, the information about user basic information such as login name, password and the information about authority was managed. There are two kinds of standards in standards management module: origin environmental standard such as water, air and soil quality standard; navel orange quality standard. The information of location and surrounding of the orchard, the quality information of irrigation water, soil and air of the orchard, and the information of orchard employee was recorded in the orchard management module. In the production control module, basic information and use information of inputs such as chemical fertilizers, pesticides, herbicides, and the information of diseases and insect was controlled [4]. The function of picking management module includes picking process information and treatment measures information of post-harvest. There are three kinds of information should be managed in processing management: enterprise information, processing information (detergent, disinfectants, and keeping fresh agent) and packing information. In the final step of safety production, storage and transportation information will be saved. 


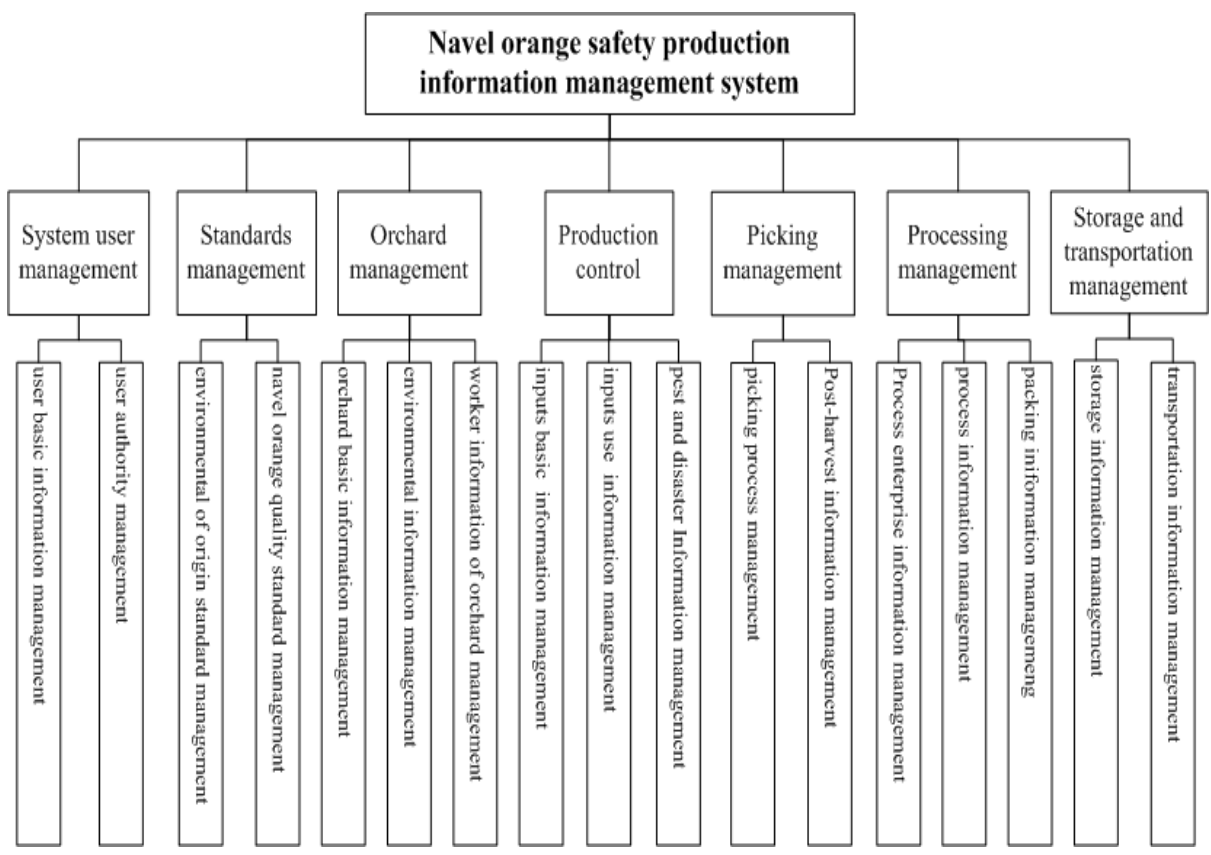

Fig. 2. Function modules of the system

\section{Implementation of Navel Orange Safety Production Information Management System}

\subsection{Implementation of User Access Authority Control}

There are many kinds of users in navel orange safety production information management system: system administrator, system operators, orchard owners, orchard workers, processing company managers, processing workers, managers of transportation enterprises, transporters. These different sorts of users have different permissions, such as system administrator has all right of the system; system operators have part right of the system administrator; an orchard owner can manage all orchards information belonging to him, but an orchard worker can only control the data of the exact orchard he have the right.

To facilitate the management, strategy of RBAC (Role Based Access Control based) is applied in this system. Different sorts of users are endowed with different permissions, each specific user can only have rights in their operations within. The workflow of loading the access and data control permissions is shown in Fig 3.

\subsection{Implementation of the System}

Navel orange safety production information system is achieved based on B/S model. Eight sort of users can login the system via one entry. The system can manage the 


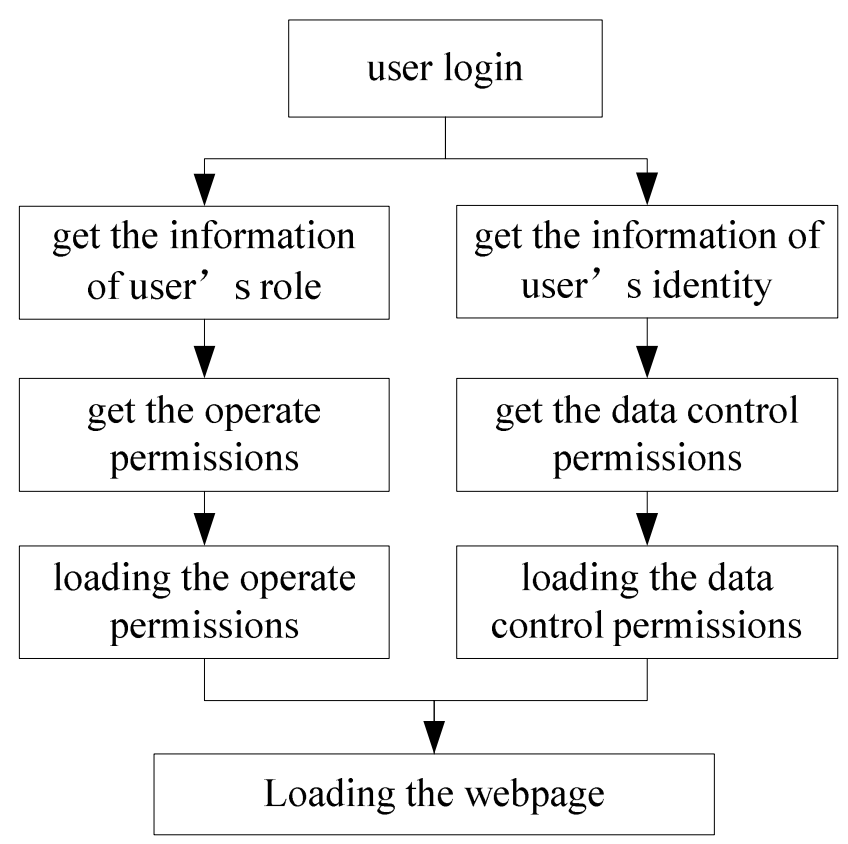

Fig. 3. Workflow of loading the permissions

information from navel tree planting to fruit transportation for many orchards, which is the foundation, and is also the core of navel orange quality safety traceability system. In the packing information management module, navel orange traceability code is generated according to the orchard code and packing batch code, by means of navel orange traceability code, consumers can get the quality safety information through the safety production information management system. The webpage of the system is shown in Fig 4.

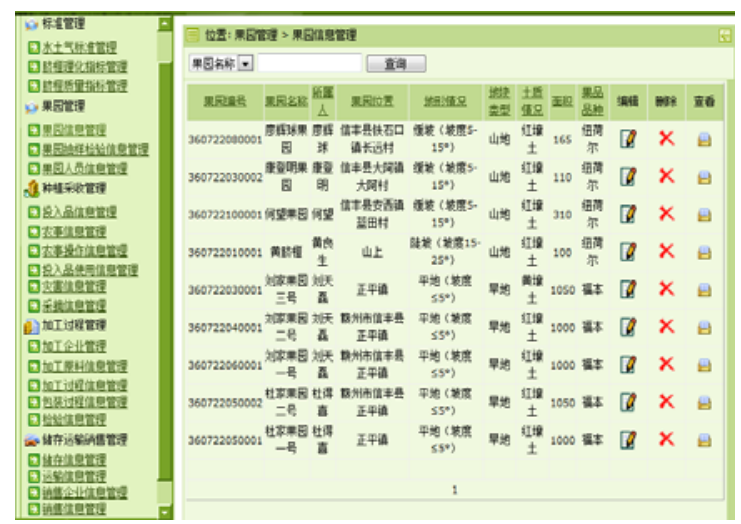

Fig. 4. Webpage of the system 


\section{Conclusion}

This paper discusses the basic function of navel orange safety production information management system based on analyses the business process from orchard selection to navel orange fruit transportation. Then introduce the principles of system design, and figure out the 7 main function modules of this system. In the end of this article, the RBAC strategy is mentioned to manage eight sorts user of navel orange safety production information management system. Navel orange safety production information management system is the core of navel orange quality safety traceability system. This study makes the navel orange traceability system construction possible.

Acknowledgements. This study is supported by The National Science and Technology Support Programme (2009BADC4B04).

\section{References}

1. Fan, H., Feng, Z., Yang, L., Ren, A.: Appliance and Discussion of Traceability System in Food Chain. Ecological Economy 17(4), 30-33 (2007)

2. Zhou, Y., Geng, X.: Application of Traceability in Food Safety. Research of Agricultural Modernization (06) (2002)

3. NY/T 977-2006.Technological regulation of navel orange cultivation in south jiangxi-south hunan-north guangxi. Publisher of China Standards (2006)

4. Zheng, H., Meng, X., Liu, S.: The Study on Navel Orange Traceability Chain. IFIP AICT, pp. 179-185 (2010)

5. $\mathrm{Xu}, \mathrm{J}$.: Agricultural product supply chain-Guarantee food safety. China Logistics \& Purchasing (07) (2005)

6. Liu, Y., Chen, L.: Traceability Production System of Beef in EU and USA, food science, vol. (8), pp. 182-185 (2003)

7. Yu, H., An, Y.: Theoretical discussion of implementation Traceability System in food supply chain. Agricultural Quality and Standards (03) (2005)

8. Zhang, G., Chen, G.: Food safety and Traceability System. China Logistics \& Purchasing (14) (2005) 